\title{
The digital marketing with the application of cloud technologies
}

\author{
Mykola Ivanov ${ }^{1, *}$ \\ ${ }^{1}$ Zaporizhzhya National University, 7, Engineer Preobrazhensky ave., Zaporizhia, 69000, Ukraine
}

\begin{abstract}
In the article, the author provides an analysis of the state of the digital economy, when the dynamics of processes in the economy are quite high and a quick analysis of multidimensional data is required, where the strategy for the production of goods and market promotion, as well as pricing, depends on consumers. The author determined that the activity of modern trading platforms is aimed at the formation of the product range and its product range with the most advantageous characteristics of the product. These requirements have a direct impact on marketing strategy and pricing at the Internet-market. The author proposed the concept of building a digital marketing system based on the theory and practice of market segmentation, which takes into account many factors: geographical, costs, time, and others. The formation of similarities in consumption and pricing in the Internet market is the unifying factor in marketing research. In this concept, the author applied the method of assessing consumer efficiency, which is based on the use of rating estimates obtained on the basis of the ranking of expert opinion. Thus, the proposed concept and method for assessing consumer demand in the target market is aimed at the perspective management of trading platforms using cloud technologies.
\end{abstract}

The digital economy opens up new directions, among which digital marketing occupies has one of the leading places.

Bill Gates in his book "Business at the speed of thought" in 1999 expressed the idea of how technology can help improve business and how it will change the nature of the company in the future. Bill Gates emphasized that "If a company is not on the Internet, then the company does not exist at all."

K. Smith [1] ten years later suggested that by 2010 the number of Internet users in the world will exceed 2 billion. And as a consequence of the rapid development of the Internet will increase the use of digital marketing that is considered as a strategic objective of any company.

J. Armitage [2] confirmed in 2015 that the digital strategy should be the main focus of any company's market strategy. J. Armitage also expressed the idea that fast developing technology will lead to new forms of business.

M. Gaikwad [3] in 2016 examined modern marketing and found that the digital marketing deserves special attention for companies.

D. Longo [4] in 2016 put forward the hypothesis that the strategy in the digital marketing should be a priority, and this is an additional way of doing business in the company.

S. Kingsnorth [5] in the course of his research in 2017 suggested the idea that digital marketing is widespread and is actual direction.

Significant contribution to theoretical and practical developments, as well as the formation of scientific fields of marketing research, sales marketing functions, business process management, information system models, optimization models for prices and sales volumes in consumer markets, marketing management functions and approaches, problem-oriented business management processes, modeling of cooperative relations in the digital economy have made works of: V. Halitsyn [6], Philip Kotler [7], V. Kravchenko [8], V. Lukyanchenko [9], Yu. Lysenko [10, 11], I. Rezhetnikova [12] and S. Ivanov [13] and others.

In modern conditions, when the dynamics of economic processes is quite high, real-time data required, where commodity production strategy, marketing promotion and pricing depend on the consumers, the more urgent task is to build digital marketing system with the use of cloud technologies.

All the activities of modern trading platforms are aimed at the formation of the product range and with the most advantageous characteristics, which are aimed at meeting the needs of the consumer. These requirements have a direct impact on marketing strategy and pricing in the Internet-market. Therefore, digital marketing has a direct connection with the customer, where the information from consumers received in real time can quickly respond to the rapidly changing demands.

The digital marketing systems allow to identify the demand and meet the needs of each individual customer. Therefore, digital marketing has become the main way to communicate with consumers in the Internet market.

The aim of the work is to develop marketing research techniques, methods of processing and analyzing information using cloud technologies in the digital economy.

It is proposed to construct the concept of marketing research based on the theory and practice of market segmentation, which takes into account the

* Corresponding author: nn_iva@ukr.net 
multidimensionality of factors: geographical, costs, time, and others.

The unifying factor in the marketing research is to develop similarities in consumption and pricing of Internet-market. These analogy are associated with the principles of similarity [7], which make products similar and form substitute products. This fully applies to goods and services, which can be considered as a target market.

Such a target market corresponds to the properties of the Internet, which is not limited to the contingent of consumers of goods, services and information resources.

The products and the services sold on the market, have a number of specific economic and social characteristics. Firstly, they have lower prices. [14] Secondly, the range of products is not restricted, only limited by the specificity of the trading platform. The digital marketing puts forward a number of requirements for the target market, which were analyzed from the position of the possibility of their implementation on trading floors (Table 1).

Table 1. Target market requirements for segmentation.

\begin{tabular}{|l|l|}
\hline The target market requirements & \multicolumn{1}{|c|}{ The restrictions } \\
\hline The profitability & $\begin{array}{l}\text { The profitability level is } \\
\text { limited }\end{array}$ \\
\hline The volume of sales & The volume of sales is limited \\
\hline The presence of competitors & $\begin{array}{l}\text { The presence of competitors } \\
\text { is limited }\end{array}$ \\
\hline $\begin{array}{l}\text { The availability of substitute } \\
\text { products }\end{array}$ & $\begin{array}{l}\text { The volume of substitutes } \\
\text { present in the target market is } \\
\text { limited }\end{array}$ \\
\hline $\begin{array}{l}\text { The lack of a "strong" position } \\
\text { of consumers }\end{array}$ & $\begin{array}{l}\text { The consumers are closely } \\
\text { related }\end{array}$ \\
\hline $\begin{array}{l}\text { The estimation of the demand } \\
\text { and satisfaction of the } \\
\text { customer's needs }\end{array}$ & $\begin{array}{l}\text { The technological capabilities } \\
\text { of trading platforms }\end{array}$ \\
\hline
\end{tabular}

The choice of the target market is carried out on the basis of the task of increasing sales. In this case, digital marketing is used, which is a multi-dimensional structure. This is due to the fact that producers and consumers are combined on the trading platform in the global Internet.

Therefore, the concept of building a digital marketing system using cloud technologies (Fig. 1) includes not only a study of the target product market, but also a solution to the analytical function of marketing (analysis, evaluation, forecasting).

In this concept, a method of assessing consumer efficiency is used, which is based on the use of rating estimates derived from the ranking of expert opinion on several scales of the order. Experts can be both consumers and manufacturers. The application of expert assessments is necessary in conditions with the Internet market. The method for assessing consumer demand in the target market is presented in Fig. 2.

The implementation of the method begins with the formation of the initial data. Further, each product is assigned an expert assessment $\left(P_{i}\right)$ on the following fivepoint scale: 5 - very high utility; 4 - high utility; 3 average utility; 2 - low utility; 1 - very low utility.
Additionally, to take into account prices and costs, a utility cost correction factor is used $\left(k_{i}\right)$, with the following values: 1.5 - the consumer is ready to pay extra for utility; 1.2 - the consumer is interested in utility, but will be interested in price; 1.0 - consumer will not pay for utility.

Absolute rating indicators of the usefulness of the product are uninformative and poorly comparable for different products, therefore, the relative indicator (utility index) is used further and is calculated by the following expression:

$$
x_{i}=\frac{P_{i} \cdot k_{i}}{\sum_{i=1}^{n} P_{i} \cdot k_{i}}
$$

where $P_{i}$ - rating score $i$ utility $(1 \ldots 5$, entire);

$k_{i}$ - coefficient, cost-based utility;

$n$ - amount of product utility;

$i=1 \ldots n$.

The formation of utility indices is the next step in measuring the consumer effect of individual market segments. For the product under consideration, the following consumer benefits are highlighted: product quality, delivery time, price policy, form of payment.

The proposed list of benefits can be expanded and specified.

The next step in the implementation of the method is to form columns of the matrix, which form innovations both that are in the arsenal and anticipated: organizational, technical, service, etc. This list may include innovations, described qualitatively, and innovations expressed by the values of technical and economic indicators.

In principle, this method can be used to synthesize innovations. In this case, the activity of the trading platform is based on the principle "what can be done (change, improve, supplement, etc.) to form a specific utility".

The elements of the matrix of size $n \times m$, where $\mathrm{m}$ is the number of innovations considered, are filled with rating estimates of the strength of influence of the $j$ innovation on the $i$ product benefit. The influence rating is set on the following ten-point scale of order: 9 strong influence; 3 - average impact; 1 - weak influence; 0 - innovation does not affect the individual benefits of the product. The formation of utility indices of commodity products is given in table 2 .

Table 2. The formation of utility indexes for evaluation consumer benefits.

\begin{tabular}{|l|c|c|c|c|}
\hline \multicolumn{1}{|c|}{$\begin{array}{c}\text { The consumer } \\
\text { benefits }\end{array}$} & $P_{i}$ & $k_{i}$ & $P_{i} k_{i}$ & $x_{i}$ \\
\hline $\begin{array}{l}\text { 1. The product } \\
\text { quality }\end{array}$ & 5 & 1,5 & 7,5 & 0,36 \\
\hline $\begin{array}{l}\text { 2. The delivery } \\
\text { time }\end{array}$ & 3 & 1,3 & 3,9 & 0,19 \\
\hline 3. The price policy & 4 & 1,3 & 5,2 & 0,25 \\
\hline $\begin{array}{l}\text { 4. The form of } \\
\text { payment }\end{array}$ & 4 & 1,0 & 4,0 & 0,2 \\
\hline & & $S$ & $\sum_{i=1}^{n} P_{i} k_{i}=20,6$ & $\sum x_{i}=1$ \\
\hline
\end{tabular}




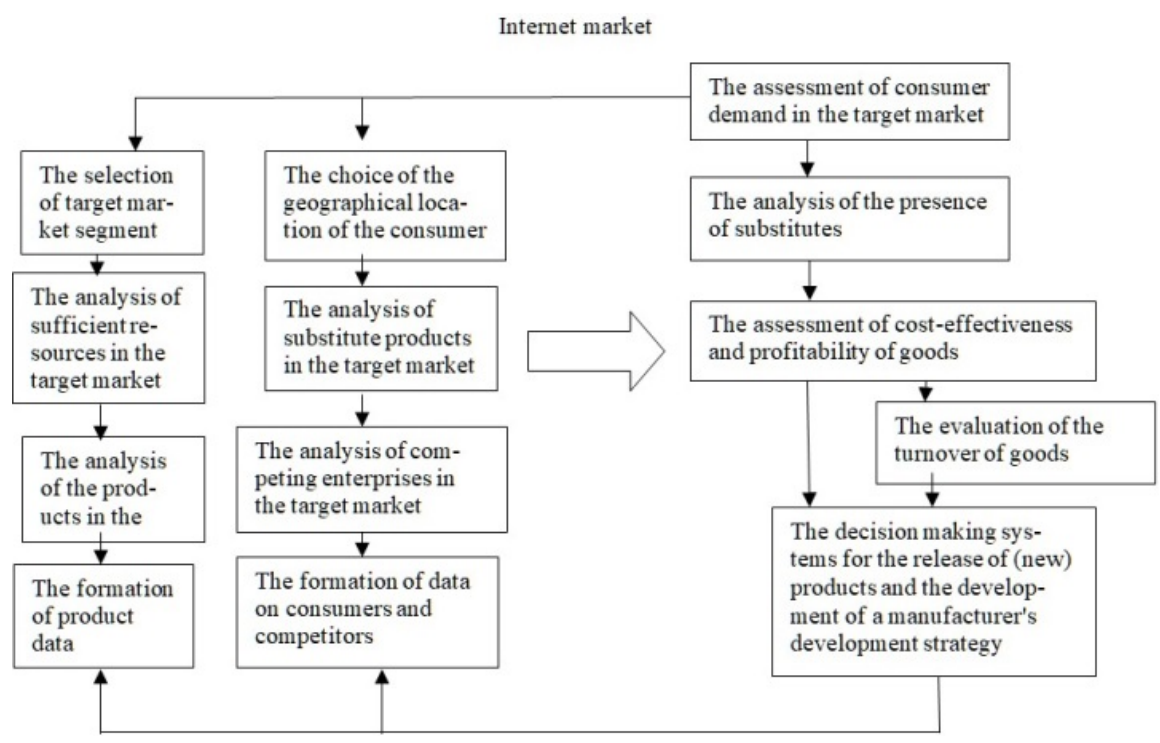

Fig. 1. The concept of building a digital marketing system using cloud technologies.

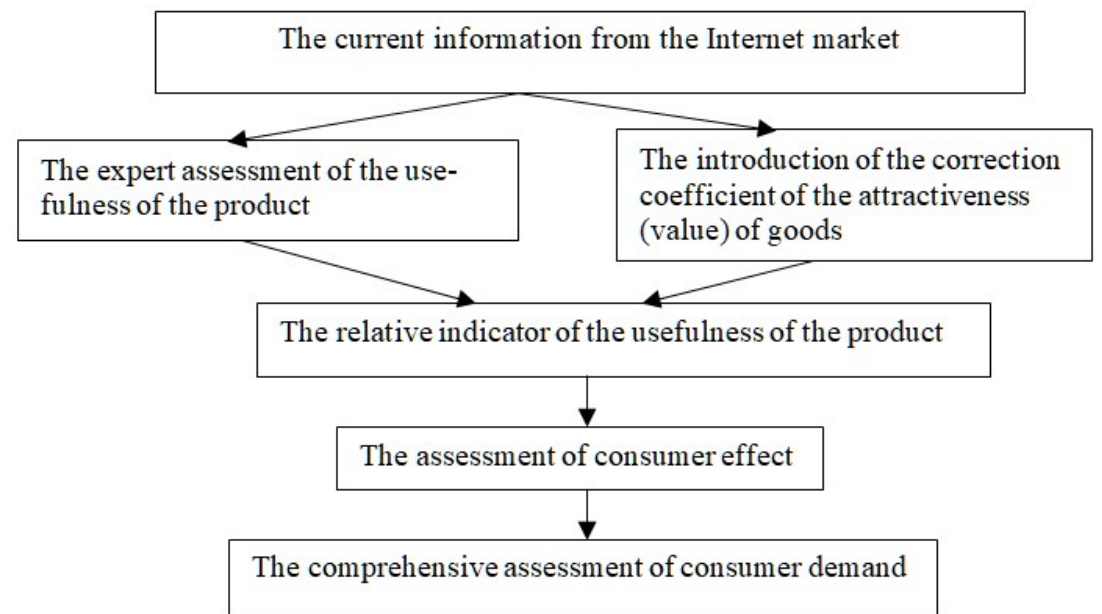

Fig. 2. The method of assessing consumer demand in the target market.

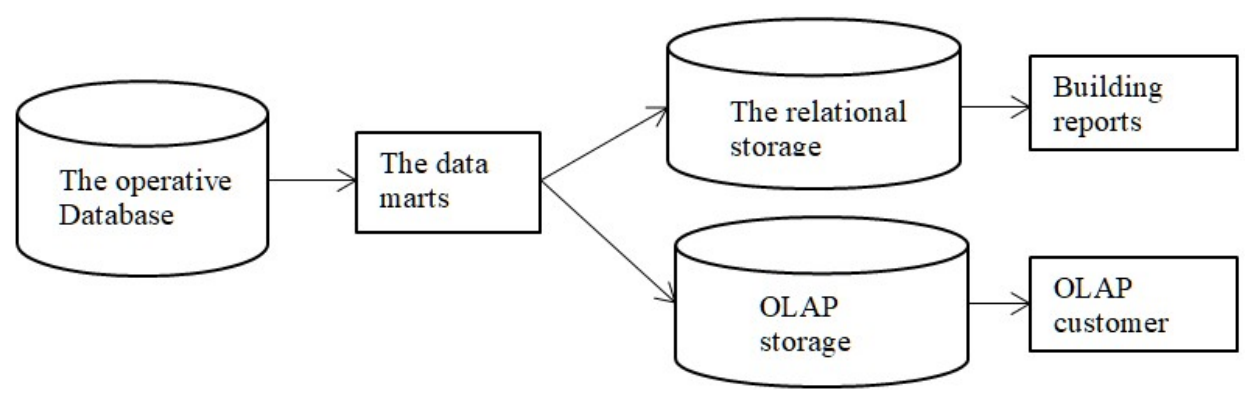

Fig. 3. Online data processing system based on OLAP technology.

Using the designation $y_{j i}$ to assess the strength of the effect of the $j$ product on the $i$ benefit, we can calculate the conditional and unconditional indices of the consumer effect of each product. Then we write the conditional index as follows:

$$
E_{j i}=\frac{\sum_{i=1}^{n} x_{i} y_{j i}}{\sum_{j=1}^{m} \sum_{i=1}^{m} x_{i} y_{j i}} .
$$

Conditional index is useful for comparative assessment of the product according to the degree of its influence on its total value.

However, the conditional index depends on the total volume of the product and shows the relative contribution of a single product to the formation of benefits and therefore cannot be used to quantify the consumer effect.

To measure a consumer effect that does not depend on the total amount, an unconditional consumer effect index is used. When constructing it as a base we use the value of the consumer effect, which have the maximum 
effect on the utility of each consumer. Then, according to expression (2), the unconditional index can be written in the following form:

$$
B_{j i}=\frac{\sum_{i=1}^{n} x_{i} y_{j i}}{\sum_{i=1}^{n} x_{i} y_{j i \max }} .
$$

Considering that in the given dependence $y_{\text {jimax }}=9$ (according to the adopted scale), the expression in the denominator also takes the value equal to 9 , i.e. $=9$, and the evaluation of the consumer effect of the $j$-th product is relative to the absolute value. The obtained data will allow the decision support management system to choose a perspective direction for the production of goods. For the considered goods in the table 3 the list of main indicators was used, a matrix was formed and conditional and unconditional indices of consumer effect were determined according to the dependencies.

Table 3. The formation of conditional and unconditional indices of consumer effect for a trading platform (Rozetka.com.ua).

\begin{tabular}{|l|c|c|c|c|c|c|}
\hline $\begin{array}{c}\text { The } \\
\text { consumer } \\
\text { benefits }\end{array}$ & $x_{i}$ & $\begin{array}{c}\text { The } \\
\text { volume } \\
\text { of } \\
\text { goods }\end{array}$ & $\begin{array}{c}\text { The } \\
\text { demand }\end{array}$ & $\begin{array}{c}\text { The } \\
\text { range of } \\
\text { trading } \\
\text { platform }\end{array}$ & $\begin{array}{c}\text { The } \\
\text { logistics } \\
\text { system }\end{array}$ & $\begin{array}{c}\text { Dealer } \\
\text { Relations }\end{array}$ \\
\hline $\begin{array}{l}\text { 1. The } \\
\text { product } \\
\text { quality }\end{array}$ & 0,36 & 8 & 9 & 9 & 7 & 5 \\
\hline $\begin{array}{l}\text { 2. The } \\
\text { delivery } \\
\text { time }\end{array}$ & 0,19 & 7 & 6 & 9 & 8 & 7 \\
\hline $\begin{array}{l}3 . \text { The } \\
\text { price } \\
\text { policy }\end{array}$ & 0,25 & 7 & 8 & - & 7 & 4 \\
\hline $\begin{array}{l}4 . \text { The } \\
\text { form of } \\
\text { payment }\end{array}$ & 0,2 & 5 & 7 & - & 8 & 9 \\
\hline & 1,0 & 6,96 & 7,78 & 4,95 & 7,39 & 5,93 \\
\hline & $E_{j i}$ & 0,21 & 0,24 & 0,15 & 0,22 & 0,18 \\
\hline & $B_{j i}$ & 0,77 & 0,86 & 0,55 & 0,82 & 0,66 \\
\hline
\end{tabular}

The results of calculations (Table 3) show steady demand (logistic system 0.82, demand 0.86 ) of the trading floor (Rozetka.com.ua).

In the future, the Internet can be effectively used for various marketing research of the Internet market. The global network provides an opportunity to conduct market research based on the current data of the product market presented on the Internet, as well as to study the composition of the real and potential groups of customers.

The extraction of the knowledge can be defined as the search and study of the marketing information. To solve these research tasks, the following approaches are used: automatic search and analysis of data on Web sites, data mining in the detection and study of the information related to the users interests in products and services.

The increase in the amount of data available on the Internet is usually stored in an unstructured form, which has contributed to the emergence of multidimensional databases, as well as tools for operational data analysis (OLAP - Online Analytical Processing technology). Today we use the systems with artificial intelligence, whose task is to efficiently extract and research data from the Internet.

The process of data mining is an integral part of the digital economy, which also analyzes the activity of consumers of goods, as well as exploring the most popular ways to visit the Internet. To solve these problems, unstructured Internet data is used. Trading platforms analyze a large amount of information and store it in multidimensional databases using cloud technologies. Sources of information are also reference websites that contain information on every page that is linked to. Sites are browsed by programs on the Internet and contain personal data of users.

The main consumers of electronic banking systems are trading platforms that sell or provide services on the Internet. The main tasks for them are the personalization of the consumer of goods and services, conducting effective advertising work and simplifying the work. Such systems are of interest to Internet providers. The main areas of application in this case are the optimization of the Internet, the minimization of traffic and the optimization of services provided using intelligent systems.

Modern Internet systems provide the ability to identify a user and obtain statistical information about a user's interests. Such software applications allow to determine the turnover, the intensity of calls to different information, addresses of individual users with the ability to analyze the relationship between references to data sources and information.

Today, obtaining information at the level of the trading platform - the consumer is the main component for developing a strategy for the work of the product manufacturer. This can be used to obtain information about the priorities and interests of consumers of the goods. In addition, one of the methods for which the study of patterns in the commodity market is the main task is Data Mining technology. Traditionally, all Internet resources automatically process events, and this information is stored in the relational databases.

The relational databases have disadvantages. The main disadvantage is the storage of the incomplete information and the impossibility of storing unstructured data. The calls to the web pages stored on Internet servers are stored in the server log, and the data is sent using the POST method. An alternative method of analyzing data on the server itself is a study at the packet level. Thus, it is possible to conduct studies at the level of individual TCP/IP requests or save such data using cloud storage.

The analysis of access to the data on the server can provide information about the consumer's interest as well as the nature of web browsing, as well as an anonymous group of the users using a single network access point. Using specialized software will help to achieve the benefits of the trading platform on the Internet. The expanding marketing research opportunities can be solved by cloud technologies (cloud storage and cloud computing).

A large amount of statistical data requires convenient presentation of information for solving marketing research. As such a platform, multidimensional 
databases (OLAP) can be used since traditional, built on the basis of relational repositories, are deprived of the opportunity. They cannot be analyzed and investigated and the result of the research can be obtained in the form of "slices" of data. OLAP is such a tool.

Although OLAP is not a necessary attribute of a data warehouse, it is increasingly used to analyze the information accumulated in this data warehouse.

The system of on-line processing of Internet data based on OLAP can be represented as follows (Fig. 3).

The operational data is collected from various sources, filtered into the data marts and stored in a relational repository. At the same time, they are already available for analysis using various report generation tools. The next step is to prepare the data for building multidimensional databases for OLAP analysis. The main element is the metadata, i.e. information on the structure, location and transformation of the data. This ensures the effective interaction of various components of the repository.

Summarizing, you can define OLAP as a combination of the multidimensional analysis of the data accumulated in the repository. OLAP provides the enterprise with the most convenient and fast means of accessing, viewing and analyzing business information. Most importantly, OLAP provides the user with a natural, intuitive data model, organizing them in the form of multidimensional cubes. The axes (dimensions) of the multidimensional coordinate system are the main attributes of the analyzed marketing process. So for the sales process it can be a product category, region, type of buyer. Almost always time is used as one of the measurements. Inside the cube there are data that quantitatively characterize the process - the so-called Measures (Measures). These can be sales in pieces or in monetary terms, stock balances, costs, and others. The user of marketing research can choose arbitrarily any "slice" in a cube of the data in different directions and receive summary information on the years, quarters, months, days that he needs for the analysis.

First of all, it should be noted that since the marketer always operates with certain summary data, so-called aggregates, that is, pre-calculated totals, are almost always stored in OLAP databases along with detailed data. The examples of aggregates can serve as the total sales for the year or the average balance of goods in stock. Storing pre-computed aggregates is the main way to increase the speed of OLAP queries.

The integration of the data warehousing with the formation systems (data marts) is a complex task, which is aimed at obtaining an exhaustive set of marketing functions. The main advantage of integration with the accounting system is the ability to quickly create for the user a set of reports and models for the study of various areas of economic activity of the trading platform.

In this case, all the efforts of the developer will be reduced to solving the problems of reengineering. The most important task is to create an efficient storefront structure. Since a regular accounting system is optimized only for storing information, the data fields are spread across thousands of tables. Therefore, the search for fields describing a specific query is both a timeconsuming and a slow process that adversely affects the performance of the database.

In fig. 4 shown the trading floor system for the sales data mart.

To optimized the coordinated storefronts is to create a structure that would allow the most expeditiously analyze the data and produce reports, quickly providing the marketer with the necessary information about the results of the analysis.

Based on the proposed concept and data processing system based on OLAP technologies, it is possible to offer the following axiomatic marketing processes:

In the digital marketing system all functional modules corresponding to the marketing functions are equivalent from the point of view of the classical approach. That is, if everyone is truly a marketing function (of a set) M (n) has the property A (), then there is a set for which $n M(n)$ is true:

$$
(n): A(\beta) \supset M(n) \rightarrow \exists n M(n)
$$

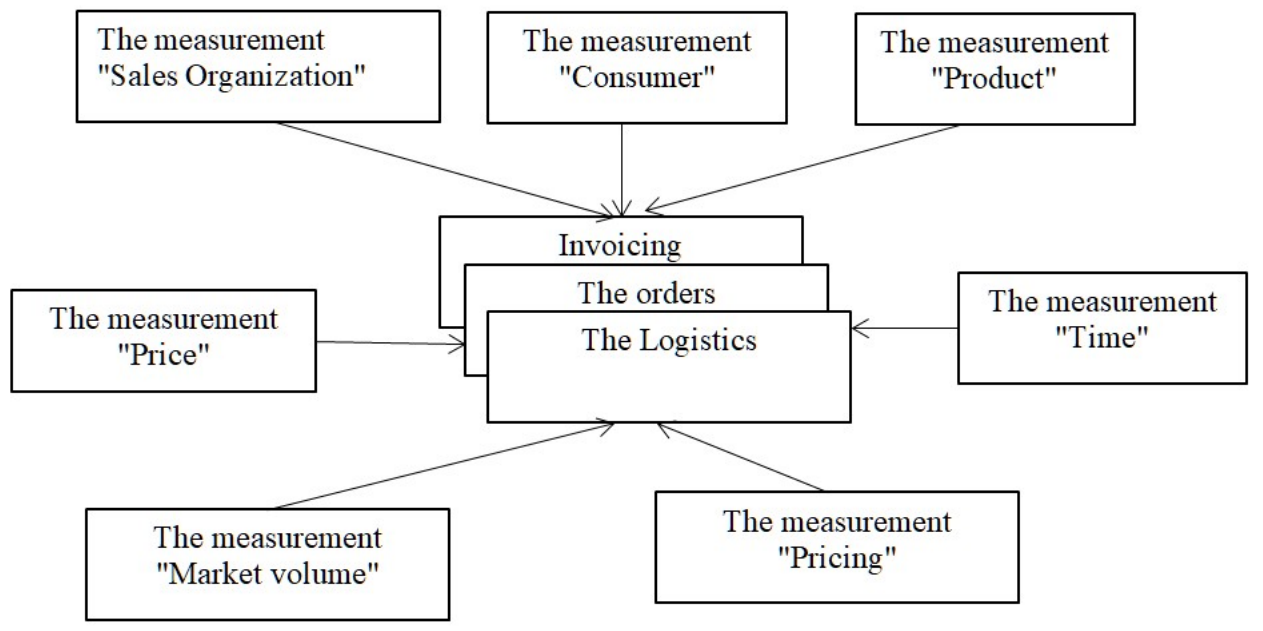

Fig. 4. The trading floor system for sales data marts. 
Formation of a multidimensional digital marketing system. In the digital marketing system, segment directions are selected, which determines the $R_{p r}$ solution. If for all intersections of the set of solutions of the digital marketing system (marketing $\mathrm{R}_{\mathrm{m}}$, logistics $\mathrm{R}_{1}$ and others) is not an empty set, then there is a marketing solution $\mathrm{R}_{\mathrm{pr}}$ :

$$
\mathrm{R}_{\mathrm{m}} \cap, \ldots, \cap \mathrm{R}_{\mathrm{l}} \rightarrow \mathrm{R}_{\mathrm{pr}}
$$

The ability to use digital marketing systems to solve problems of analysis, management, sales and control, taking into account the development of the target market, consumer demand, product range, competitors and others:

$$
\mathrm{S}(\mathrm{m})=\{\mathrm{S}(\mathrm{i}), \ldots, \mathrm{S}(\mathrm{l})\} .
$$

Thus, the proposed approach and method for assessing consumer demand in the target market is aimed at managing trading platforms with regard to marketing research and involves the use of digital marketing systems. There have been analyzed and proposed a marketplace system for the sales data mart using OLAPtechnology. The axiomatic marketing processes are proposed.

\section{References}

1. Smith, K.T.: Digital marketing strategies that millennials find appealing, motivating, or just annoying. Journal of Strategic Marketing, 19(6), 489-499

(2011). doi:10.1080/0965254X.2011.581383

2. Armitage, J.: Strategic insights. Marketing Insights, 27(1), 22-23 (2015)

3. Gaikwad, M., Kate, P. H.: E-marketing: A modern approach of business at the door of consumer clear. International Journal of Research in Commerce \& Management. 7(9), 56-61 (2016)

4. Longo, D.: Why Strategy Must Come First in Digital Marketing. Convenience Store News, 52(5), 57-60 (2016)

5. Kingsnorth, S.: Digital Marketing Strategy: An Integrated Approach to Online Marketing. Kogan Page, London (2017)

6. Halitsyn, V.K., Kaminsky, O.E.: Monitoring of cloud services deployed in a multi-cloud environment. Modeling and Information Systems in Economics. 94, 160-169 (2017)

7. Kotler, P., Keller K.L.: Marketing Management. Pearson India, Chennai (2017)

8. Kravchenko, V.N.: Tools for problem-oriented business process management. Dnepropetrovsk (2014)

9. Lukyanchenko, V.V.: Marketing approaches in the management of a production enterprise with an innovative resource and in the formation of a new business model. Business Inform. 4, 154-158 (2011)
10. Lysenko, Yu.G., Andrienko, V.N., Ivanov, N.N.: Computer science and computer technology: Ecommerce. South-East Ltd, Donetsk (2004)

11. Lysenko, Yu.G., Guz, N.G., Ivanov, N.N.: Management of the marketing potential of an enterprise. South-East Ltd, Donetsk (2005)

12. Rezhetnikova, I.L.: Marketing in direct logistics channels: current trends. Marketing in Ukraine. 1(88), 46-53 (2015)

13. Ivanov, S.M.: Modeling of cooperative connections in the digital economy. Modeling and Information Systems in Economics. 96, 108-117 (2018)

14. Ivanov, N.N.: Information and analytical systems in the management of economic objects. Business Inform. 10(429), 141-145 (2013) 